\title{
Classification of maternal mortality by ICD-MM: a retrospective study from a tertiary care hospital of Chhattisgarh
}

\author{
Anju R. Ekka*, Sangeeta R. Jogi
}

Department of Obstetrics and Gynaecology, Chhattisgarh Institute of Medical Sciences, Bilaspur, Chhattisgarh, India

Received: 15 December 2020

Accepted: 31 December 2020

*Correspondence:

Dr. Anju R. Ekka,

E-mail: dranju.ekka@gmail.com

Copyright: (C) the author(s), publisher and licensee Medip Academy. This is an open-access article distributed under the terms of the Creative Commons Attribution Non-Commercial License, which permits unrestricted non-commercial use, distribution, and reproduction in any medium, provided the original work is properly cited.

\begin{abstract}
Background: Sustainable development goal 3 (SDG 3) includes an ambitious target of reducing the global maternal mortality rate (MMR) to less than 70 per 100000 births by 2030. To reach this target, countries need an accurate picture of the levels and causes of maternal deaths. A standardization of the cause of death attribution will improve interpretation of data on maternal mortality, analysis on the causes of maternal death, and allocation of resources and programmes intended to address maternal mortality. International classification of diseases-maternal mortality (ICD$\mathrm{MM}$ ) has proven to be easily applicable and helps clarify the cause of maternal death.

Methods: Retrospective study of 142 maternal death cases was done in a tertiary medical centre (medical college) from December 2017 to November 2020 for determining the causes of maternal death and their classification according to ICD-MM.

Results: Direct causes of maternal deaths were observed in $82.39 \%$ cases whereas indirect causes were present in remaining $17.61 \%$ cases. Hypertensive disorders $(35.92 \%)$, obstetric haemorrhage $(26.06 \%)$ and pregnancy related infection (14.79\%) constituted the major groups of direct cause of maternal deaths whereas anaemia was the most common indirect cause $(7.75 \%)$.

Conclusions: Hypertensive disorders $(35.92 \%)$, obstetric haemorrhage $(26.06 \%)$ and pregnancy related infection $(14.79 \%)$ were the major causes of direct obstetric death and anaemia $(7.75 \%)$ was the most common cause of indirect obstetric death. All of these causes are preventable with targeted interventions. Reducing maternal mortality is one of the key targets within the SDG and ICD-MM is a valuable tool for uniform and standard classification of maternal deaths as well as for developing strategies for reducing maternal death. Training on cause of death certification, maternal death surveillance and response (MDSR) documentation and use of ICD is essential to enable consistent application of ICD coding and improve data collection and analysis.
\end{abstract}

Keywords: MDSR, ICD-MM, Underlying cause of death, Direct obstetric death, COVID-19

\section{INTRODUCTION}

The World Health Organization (WHO) defines maternal death as: the death of a woman while pregnant or within 42 days of termination of pregnancy, irrespective of the duration and site of the pregnancy, from any cause related to or aggravated by the pregnancy or its management but not from unintentional or incidental causes. ${ }^{1}$ This definition allows identification of a maternal death, based on the cause of the death being recorded as either a direct or indirect maternal cause. The WHO application of international classification of diseases-10 (ICD-10) to deaths during pregnancy, childbirth, and the puerperium: international classification of diseases-maternal mortality (ICD-MM) is intended to facilitate the consistent collection, analysis and interpretation of information on maternal deaths. ${ }^{2}$

Ending preventable maternal mortality (EPMM) is one of the most challenging tasks in most of the country. ${ }^{3}$ 
Sustainable development goal (SDG) 3 includes an ambitious target of reducing the global maternal mortality rate (MMR) to less than 70 per 100000 births by 2030 with no country having a maternal mortality greater than 140, a number twice the global average. ${ }^{1}$ To reach this target, countries need to identify real clinical causes and health system shortfalls to reduce complications and adverse fatal outcome in pregnancy. A standardization of the cause of death attribution will improve interpretation of data on maternal mortality, analysis on the causes of maternal death, and allocation of resources and programmes intended to address maternal mortality. ${ }^{2}$

Maternal death surveillance and response (MDSR) is a continuous cycle of identification, notification and review of maternal deaths followed by actions to improve quality of care and prevent future deaths. ${ }^{4}$ MDSR guidelines recommend that maternal deaths must be classified on the basis of ICD-10. ${ }^{4}$ The causes of maternal mortality vary greatly across region and limited studies are available in context of application of ICD-MM in classification of maternal mortality. With this background the following study was undertaken in the department of obstetrics and gynaecology, Chhattisgarh institute of medical sciences with the following objectives: to classify the underlying causes of maternal death according to ICD-MM, and to categorize maternal death into direct or indirect obstetric death.

\section{METHODS}

The present study was a retrospective study carried out in the department of obstetrics and gyanecology at Chhattisgarh institute of medical sciences which is a government medical college and second biggest tertiary care centre of Chhattisgarh. It has an annual delivery rate of around 5500 and gets a large number of referrals from primary health centres (PHCs), community health centres (CHCs), as well as district hospitals.

The details of all the maternal deaths from December 2017 to November 2020 were collected from the individual case sheets, facility-based maternal death review form and MDR case summary. The WHO application of ICD-10 to deaths during pregnancy, childbirth and the puerperium: ICD-MM was used for classification of causes of maternal mortality. The MDSR form was filled within 24 hours of death and reviewed by the facility maternal death review committee and the Institutional death review committee.

\section{Inclusion criteria}

All cases of maternal death fulfilling the WHO definition of maternal death and having complete data on MDSR form were included in the study.

\section{Exclusion criteria}

The following cases were excluded from the study: maternal death occurring after 42 days after termination of pregnancy, maternal death due to accident, homicide or suicide, and maternal death for which data was incomplete or missing.

The definitions of causes of death as per ICD-MM are stated below.

\section{Underlying cause of death}

It is defined as the disease or condition that initiated the morbid chain of events leading to death or the circumstances of the accident or violence that produced a fatal injury.

\section{Direct obstetric deaths}

Direct obstetric deaths are those resulting from obstetric complications of the pregnancy state (pregnancy, labour and the puerperium), from interventions, omissions, incorrect treatment, or from a chain of events resulting from any of the above.

\section{Indirect obstetric deaths}

Indirect obstetric deaths are those resulting from previous existing disease or disease that developed during pregnancy and which was not due to direct obstetric causes, but which was aggravated by physiologic effects of pregnancy.

\section{Contributing causes}

It may predispose women to death, as either a pre-existing condition or a risk factor.

A total of 142 maternal mortality cases were analyzed in this study for causes of death. Single cause coding was done and underlying cause was determined for each maternal death. Cases were further categorized into direct and indirect obstetric death based on single underlying cause. Contributory causes for each case were also evaluated. All the data was presented as frequencies and percentages.

\section{RESULTS}

Classification of causes of death according to WHO ICDMM is represented in Table 1 . Direct causes of maternal deaths were observed in $82.39 \%$ cases whereas indirect causes were present in remaining $17.61 \%$ cases (Table 2 and Table 3 respectively). Hypertensive disorders (35.92\%), obstetric haemorrhage $(26.06 \%)$ and pregnancy related infection $(14.79 \%)$ constituted the major groups of direct cause of maternal deaths whereas anaemia was the most common indirect cause $(7.75 \%)$. Severe preeclampsia $(19.01 \%)$, puerperal sepsis $(14.79 \%)$ and postpartum haemorrhage $(13.38 \%)$ were the significant underlying causes. During the study period, two cases of maternal death with COVID-19 were noted. COVID-19 was attributable to underlying cause in one case due to 
development of pneumonia which led to death (Table 3). COVID-19 was assigned as contributory cause in another case because the underlying cause of death was abruptio placenta. Two cases earlier grouped in 'Other obstetric complications' (group 5) were reclassified as aspiration pneumonitis (group 6) (Table 2).

Table 1: Classification of maternal deaths according to WHO ICD-MM (n=142).

\begin{tabular}{|llll|}
\hline Type & Group name (number) & Cases & $\begin{array}{l}\text { Percentage } \\
(\%)\end{array}$ \\
\hline Maternal death: direct & Pregnancy with abortive outcome (1) & 4 & 2.82 \\
\hline Maternal death: direct & Hypertensive disorders in pregnancy, childbirth and puerperium (2) & 51 & 35.92 \\
\hline Maternal death: direct & Obstetric haemorrhage (3) & 37 & 26.06 \\
\hline Maternal death: direct & Pregnancy related infection (4) & 21 & 14.79 \\
\hline Maternal death: direct & Other obstetric complications (5) & 2 & 1.41 \\
\hline Maternal death: direct & Unanticipated complications of management (6) & 2 & 1.41 \\
\hline & Non obstetric complications (7) & 25 & 17.61 \\
\cline { 2 - 4 } & Anaemia & 11 & 7.75 \\
\cline { 2 - 4 } Maternal death: & Cardiac disorders & 2 & 1.41 \\
\cline { 2 - 4 } indirect & Liver disorders & 2 & 1.41 \\
\cline { 2 - 4 } & Respiratory disorders & 6 & 4.23 \\
\cline { 2 - 4 } & Neurological disorders & 2 & 1.41 \\
\cline { 2 - 4 } & Infections/infestations & 2 & 1.41 \\
\hline
\end{tabular}

Table 2: Distribution of underlying causes of direct obstetric death $(n=142)$.

\begin{tabular}{|c|c|c|}
\hline $\begin{array}{l}\text { Causes of direct obstetric } \\
\text { death }\end{array}$ & Cases & $\begin{array}{l}\text { Percentage } \\
(\%)\end{array}$ \\
\hline \multicolumn{3}{|c|}{ Pregnancy with abortive outcome } \\
\hline Incomplete abortion & 3 & 2.11 \\
\hline Septic abortion & 1 & 0.70 \\
\hline \multicolumn{3}{|c|}{$\begin{array}{l}\text { Hypertensive disorders in pregnancy, childbirth } \\
\text { and puerperium }\end{array}$} \\
\hline Severe preeclampsia & 27 & 19.01 \\
\hline Eclampsia & 24 & 16.90 \\
\hline \multicolumn{3}{|l|}{ Obstetric haemorrhage } \\
\hline $\mathrm{PPH}$ & 19 & 13.38 \\
\hline Ruptured uterus & 10 & 7.04 \\
\hline Placenta previa & 3 & 2.11 \\
\hline Abruptio placenta & 5 & 3.52 \\
\hline \multicolumn{3}{|l|}{ Pregnancy related infection } \\
\hline Puerperal sepsis & 21 & 14.79 \\
\hline \multicolumn{3}{|c|}{ Other obstetric complications } \\
\hline Amniotic fluid embolism & 2 & 1.41 \\
\hline \multicolumn{3}{|c|}{ Unanticipated complications of management } \\
\hline Aspiration pneumonitis & 2 & 1.41 \\
\hline
\end{tabular}

We experienced difficulties while assigning the underlying cause in presence of multiple causes and also for determining the indirect cause of death. Analysis of the case summary and sequence of development of complications facilitated identification of one underlying cause according to the ICD-MM for each case of maternal death.

It was also noted that junior faculty had lack of knowledge for documentation of MDSR form and assigning the cause of death.
Table 3: Distribution of underlying causes of indirect obstetric death $(n=142)$.

\begin{tabular}{|ll|l|}
\hline $\begin{array}{l}\text { Causes of indirect obstetric } \\
\text { death }\end{array}$ & Cases & $\begin{array}{l}\text { Percentage } \\
(\%)\end{array}$ \\
\hline $\begin{array}{l}\text { Anaemia } \\
\text { Iron/folic acid deficiency } \\
\text { anaemia }\end{array}$ & 9 & 6.34 \\
\hline Sickle cell anaemia & 2 & 1.41 \\
\hline Cardiac disorders & & \\
\hline Myocardial infarction & 1 & 0.70 \\
\hline RHD & 1 & 0.70 \\
\hline Hepatic disorders & & \\
\hline Hepatitis & 2 & 1.41 \\
\hline Respiratory disorders & & \\
\hline Pneumonia & 3 & 2.11 \\
\hline ARDS & 2 & 1.41 \\
\hline Pulmonary embolism & 1 & 0.70 \\
\hline Neurological disorders & & \\
\hline Meningitis & 1 & 0.70 \\
\hline Stroke & 1 & 0.70 \\
\hline Infections/infestations & & \\
\hline Typhoid & 1 & 0.70 \\
\hline COVID-19 & 1 & 0.70 \\
\hline
\end{tabular}

\section{DISCUSSION}

In the present study, analysis of 142 cases was done from December 2017 to November 2020 for classification of the underlying causes of maternal death according to ICD$\mathrm{MM}$ and categorization of each maternal death into direct or indirect obstetric death.

Direct causes of maternal mortality were present in $82.39 \%$ cases whereas indirect causes were responsible for 
$17.61 \%$ cases of maternal mortality. In this study, hypertensive disorders $(35.92 \%)$ was the major direct cause of maternal death which is similar to the earlier study by Mittal et al $(28.02 \%) .^{5}$ In our study, obstetric haemorrhage $(26.06 \%)$ was the second major cause followed by pregnancy related infection (14.79\%). A WHO systemic analysis on global causes of maternal deaths revealed haemorrhage as the major causes of maternal mortality worldwide. ${ }^{6}$ Obstetric haemorrhage has also been reported as the leading cause of maternal deaths in India $(38 \%)$ as well as in the study by Sheth et al $(23.80 \%)^{3,4}$

Anaemia was the most common indirect cause $(7.75 \%)$ which is consistent with the preceding studies. ${ }^{3,5}$ The triad of hypertension, haemorrhage and sepsis is the leading cause of maternal deaths. ${ }^{3-6}$ Severe preeclampsia (19.01\%), puerperal sepsis $(14.79 \%)$ and postpartum haemorrhage $(13.38 \%)$ were the significant underlying causes in the present study. The distribution of causes and type of maternal death in the present study is consistent with the current literature in global causes of maternal death with $73 \%$ of all maternal deaths were due to direct obstetric causes whereas deaths due to indirect causes accounted for $27.5 \%{ }^{6}$

This study highlights importance of maternal death review from unusual causes such as observed during pandemic. During the study period, two cases of maternal death with COVID-19 were noted and the recent WHO guidelines for coding of COVID-19 as a cause of death was used to assign the underlying cause and contributory cause. ${ }^{7}$ COVID-19 was attributable to underlying cause in one case due to development of pneumonia leading to maternal death. COVID-19 was assigned as contributory cause in another case because the underlying cause of death was abruptio placenta.

Implications of reclassification of maternal mortality by ICD-MM have been assessed by various studies. A regional study from Sri Lanka reported a 57\% increase in the number of maternal deaths due to reclassification of 18 maternal suicides which had previously been classified as coincidental. ${ }^{8}$ The impact of reclassifying maternal deaths according to ICD-MM in UK was minimal. ${ }^{9}$ Sheth et al reassigned six cases of maternal death to the group 'unanticipated complications of management'. ${ }^{3}$ In the present study, only two cases which were earlier grouped in 'other obstetric complications' were reclassified as aspiration pneumonitis and therefore no major influence of reclassification was observed.

In this study, we experienced difficulties while assigning the underlying cause in presence of multiple causes and also for determining the indirect cause of death. The study by Mgawadere et al showed complete agreement for direct maternal deaths whereas weak agreement for other causes and for indirect maternal deaths. ${ }^{10}$ In the present study, it was also noted that junior faculty had lack of knowledge for documentation of MDSR form and assigning the cause of death. Our findings are consistent with existing studies which have observed lack of clarity on the concept of underlying cause of death and contributory conditions. . $^{3,10}$

Precise clinical knowledge is required for analyzing the course of events around maternal death and assigning a group and underlying cause for each case. There remains apparent confusion between symptoms, signs and diseases, and which conditions should be reported and accordingly tabulated as cause of death. ${ }^{2}$ Mgawadere et al have reported poor agreement between cause of death assigned by a facility based maternal review team and an expert panel. ${ }^{10}$ They observed that review team considered $36 \%$ of maternal deaths to be indirect whereas the expert panel considered only $17.4 \%$ to be indirect maternal deaths.

Reporting errors whether incompleteness or misclassification of causes of maternal death continue to pose a major challenge to data accuracy. ${ }^{1}$ An Indian analysis of the data on maternal death reviews submitted by states/union Territories in the health management information system for 2015-2016 shows that more than $60 \%$ of the maternal deaths have been classified as others. ${ }^{4}$ The inconsistency of reporting, poor quality and coverage of maternal mortality surveillance continues to limit effective implementation of prevention and control strategies of maternal mortality and morbidity. ${ }^{8}$

Consistent use of ICD-MM requires adequate training of health care providers in the attribution and classification of cause of maternal death generally as well as in how to apply the ICD-MM tool. ${ }^{3,10,11}$ A pilot study on application of ICD-MM classification system has recommended that a one-page summary of the ICD-10 classification should form part of each country's maternal death audit form so that the maternal death audit committee can refer to it during maternal death review meetings. ${ }^{11}$

Counting maternal deaths is important and more important is identifying actions to improve care, implementing those actions and monitoring the impact on maternal death. ${ }^{9}$ Hypertension, haemorrhage, sepsis and anaemia are preventable causes of maternal death. Strategies towards ending preventable maternal mortality has been introduced by WHO which is based on preventive and primary reproductive health care services, comprehensive sexuality education, family planning and contraception as well as adequate care during pregnancy, childbirth and the postpartum period. ${ }^{12}$ As direct maternal deaths decrease because of targeted interventions, efforts to reduce maternal mortality have to be focussed on reduction of indirect causes. ${ }^{6}$ Addressing the needs of women with preexisting comorbid disorders such as cardiac disorders, pulmonary disorders and neurological disorders in pregnancy will need additional link between obstetrics and other medical specialities to coordinate specialised care.

Present study is a retrospective hospital-based study with a small sample therefore the results could not be generalized. Despite this limitation, this study is one of the 
few studies from India conducted on application of ICD$\mathrm{MM}$ and therefore it provides insight on classification of maternal deaths into direct and indirect obstetric deaths based on underlying causes. This study also highlights importance of maternal death review from unusual causes such as COVID-19.

\section{CONCLUSION}

Hypertensive disorders (35.92\%), obstetric haemorrhage $(26.06 \%)$ and pregnancy related infection (14.79\%) were the major causes of direct obstetric death and anaemia $(7.75 \%)$ was the most common cause of indirect obstetric death. All of these causes are preventable with targeted interventions. Reducing maternal mortality is one of the key targets within the SDGs and ICD-MM is a valuable tool for uniform and standard classification of maternal deaths as well as for developing strategies for reducing maternal death. Training on cause of death certification, MDSR documentation and use of ICD is essential to enable consistent application of ICD coding and improve data collection and analysis.

Funding: No funding sources Conflict of interest: None declared

Ethical approval: The study was approved by the Institutional Ethics Committee

\section{REFERENCES}

1. Trends in maternal mortality: 2000 to 2017: estimates by WHO, UNICEF, UNFPA, World Bank Group and the United Nations Population Division. Available at: www.who.int/reproductivehealth/publications/matern al-mortality-2017/en/. Accessed on: 03 July 2020.

2. World Health Organization. The WHO Application of ICD-10 to Deaths During Pregnancy, Childbirth and the Puerperium: ICD-MM. Geneva, Switzerland: World Health Organization, 2012. Available at: www.who.int/reproductivehealth/publications/monit oring/9789241548458/en/. Accessed on: 01 October 2019.

3. Sheth TM, Vaishnav PP, Maitra NK. Assessing the new ICD-MM classification for assigning the cause of maternal mortality at a tertiary centre in Western India: a retrospective study. Int J Reprod Contracept Obstet Gynecol. 2019;8:3629-34.

4. Government of India. Guidelines for Maternal Death Surveillance and Response Available at: http://www.nhm.gov.in/images/pdf/programmes/mat ernalhealth/guidelines/Guideline_for_MDSR.pdf. Accessed on: 18 April 2018.

5. Mittal P, Kapoor G, Kumari N, Bajaj B. Review of Maternal Mortality at a Tertiary Care Hospital: What Have we Achieved? J Obstet Gynaecol India. 2019;69(2):149-54.

6. Say L, Chou D, Gemmill A, Tunçalp O, Moller AB, Daniels J, et al. Global causes of maternal death: a WHO systematic analysis. Lancet Glob Health. 2014;2(6):323-33

7. World Health Organization. International guidelines for certification and classification (coding) of COVID-19 as cause of death. Available at: https://www.who.int/classifications/icd/Guidelines_ Cause_of_Death_COVID-19.pdf?ua=1. Accessed on: 20 November 2020.

8. Agampodi S, Wickramage $\mathrm{K}$, Agampodi $\mathrm{T}$, Thennakoon U, Jayathilaka N, Karunarathna D, et al. Maternal mortality revisited: the application of the new ICD-MM classification system in reference to maternal deaths in Sri Lanka. Reprod Health. 2014;11(1):17.

9. Knight M, Nair M, Brocklehurst P, Kenyon S, Neilson $\mathrm{J}$, Shakespeare $\mathrm{J}$, et al. Examining the impact of introducing ICD-MM on observed trends in maternal mortality rates in the UK 2003-13. BMC Pregnancy Childbirth. 2016;16(1):178.

10. Mgawadere F, Unkels R, van den Broek N. Assigning cause of maternal death: a comparison of findings by a facility-based review team, an expert panel using the new ICD-MM cause classification and a computerbased program (interval-4). BJOG. 2016;123:164753.

11. Ameh C, Adegoke A, Pattinson RC, van den Broek N. Using the new ICD-MM classification system for attribution of cause of maternal death - a pilot study. BJOG. 2014;121(4):32-40.

12. World Health Organization. Strategies toward Ending Preventable Maternal Mortality. Geneva: World Health Organization; 2015. Available at: http://who.int/reproductivehealth/topics/maternal_per inatal/epmm/en/. Accessed on: 28 August 2020.

Cite this article as: Ekka AR, Jogi SR.

Classification of maternal mortality by ICD-MM: a retrospective study from a tertiary care hospital of Chhattisgarh. Int J Reprod Contracept Obstet Gynecol 2021;10:492-6. 